\title{
Borderline Personality Disorder: Is Diagnosis Offering Service or Stigma?
}

\author{
Victoria Rose Myers, $\mathrm{BSc}^{1}$ \\ ${ }^{1}$ Faculty of Medicine, University of Ottawa
}

A B S TR A C T

Borderline personality disorder (BPD) is a common diagnosis I encountered while on my psychiatry rotation. The stigma surrounding the diagnosis and the negative attitudes of health care professionals towards these patients raised interesting questions regarding the approach to and benefit of formal diagnosis. Through reflection, two important learning points are proposed: be aware of the stigma towards BPD patients and approach each patient with an open mind and a professional attitude, and carefully examine the context of BPD symptoms before attributing a patient's difficulties to a single diagnosis.

\section{RÉ S U É}

Le trouble de la personnalité limite (TPL) est un diagnostic commun que j’ai croisé au cours de mon stage en psychiatrie. La stigmatisation entourant ce diagnostic et les attitudes négatives des professionnels de la santé face à ces patients soulèvent d'intéressantes questions quant à l'avantage d'établir un diagnostic officiel et l'approche à suivre pour y arriver. À la suite de réflexions, deux éléments importants à retenir sont suggérés : être conscient de la stigmatisation envers les patients avec le TPL et approcher chaque patient avec un esprit ouvert et une attitude professionnelle, et examiner attentivement le contexte entourant les symptômes du TPL avant d'attribuer les difficultés des patients à un seul diagnostic.

One of the most common diagnoses I was exposed to on my psychiatry rotation was borderline personality disorder (BPD). While the exposure gave me insight into the components of this illness, it also left me with some uncomfortable questions to reflect on. Borderline personality disorder is an illness characterized by difficulties with interpersonal relationships, self-image, emotional lability, and impulsivity. As with all personality disorders, the pattern of difficulties is inflexible and pervasive across a variety of social and personal situations and can be traced back to early adulthood (Figure 1) [1]. The McLean BPD screening questionnaire is a tool used clinically to assess the presence of the DSM $\mathrm{V}$ criteria and make a diagnosis - this was used in all the clinical encounters I observed.

The lifetime prevalence of BPD is estimated to be up to 5.9\% [2]. BPD is one of the most commonly diagnosed personality disorders and makes up $10 \%$ of psychiatric outpatients and up to $20 \%$ of psychiatric inpatients [1,3]. Management of a BPD patient in crisis can be difficult as it is thought that admission to hospital is often anti-therapeutic, as it can result in further attention seeking, acting out, and self-harm behaviour. However, it is pertinent to note that a long-term study has found that patients with BPD have a suicide rate of approximately $10 \%$ [4]. Consequently, the decision of whether to admit a suicidal patient with BPD to hospital or not is an extremely difficult one that psychiatrists and emergency room physicians face on a daily basis.

The gold standard treatment for BPD is dialectical behavioural therapy (DBT). DBT is a type of cognitive behavioural therapy
A pervasive pattern of instability of interpersonal relationships, self-image, and affects, and marked impulsivity, beginning by early adulthood and present in a variety of contexts, as indicated by five (or more) of the following:

1. Frantic efforts to avoid real or imagined abandonment. 2. A pattern of unstable and intense interpersonal relationships characterized by alternating between extremes of idealization and devaluation.

3. Identity disturbance: markedly and persistently unstable self-image or sense of self.

4. Impulsivity in at least two areas that are potentially self-damaging (e.g., spending, sex, substance abuse, reckless driving, binge eating).

5. Recurrent suicidal behavior, gestures, or threats, or self-mutilating behavior.

6. Affective instability due to a marked reactivity of mood (e.g., intense episodic dysphoria, irritability, or anxiety usually lasting a few hours and only rarely more than a few days).

7. Chronic feelings of emptiness.

8. Inappropriate, intense anger or difficulty controlling anger (e.g., frequent displays of temper, constant anger, recurrent physical fights).

9. Transient, stress-related paranoid ideation or severe dissociative symptoms.

Figure 1. DSM-V Criteria for Borderline Personality Disorder

Keywords: Psychiatry; Medical student; Stigma; Borderline; Personality 
(CBT) that emphasizes the acquisition of new skills to better manage dangerous behaviours, interpersonal relationships, and emotional regulation. Several studies have supported the use of DBT in patients with BPD $[5,6]$.

During my time spent in psychiatry, a standard psychiatric clinical interaction was as follows: the patient arrived for the consult and had already been started on an SSRI or SNRI by their family physician. Their family physician would often request a formal diagnosis and advice regarding management. In the 90-minute consultation a full history was taken. The majority of patients that were diagnosed with BPD had had tumultuous childhoods and had experienced various forms of abuse. The McLean BPD screen was often used and the psychiatrist brought up the phrase 'I hate you but don't leave me'. This is a phrase commonly associated with BPD, attempting to summarize the difficulty with emotional regulation and interpersonal relationships. Patients are often asked if they can identify with this statement as a way to explore their symptoms further. At the end of consultation, a medication review was done, and they were given a referral for DBT in the community. A consult letter was written to their family doctor giving the diagnosis of BPD. The patient's chart now permanently carried the words borderline personality disorder.

Perhaps I am simplifying the consultation, but I often wondered at the end of the 90 minutes if we were doing these patients a service by diagnosing them with a label that carries a negative connotation in both the medical and real world. I am not alone in my discomfort; several health professionals around the world have discussed stigma associated with BPD-held largely by other health professionals [7]. Stigma within the health care system against borderline personality disorder has been studied amongst different groups of health care workers. A study by Markham \& Trower (2003) demonstrated that when comparing patients with BPD to patients with depression or schizophrenia, nursing staff felt that the patients with BPD were more in control of their negative behaviour and felt less sympathy and less optimism towards these patients [8]. Qualitative analyses revealed common vocabulary used by psychiatrists and emergency room physicians when describing BPD patients: 'they are manipulative', 'they are time consuming', 'they are a waste of my time', and 'I find them too difficult to deal with' [9]. There is some thought that by reacting negatively and distancing themselves from patients, health care providers are propagating the negative behaviours characteristic of BPD such as attention seeking [10]. There is early evidence that increasing health care worker education about BPD improves attitudes, but education programs specific to BPD are few and far between [11].

A patient in a follow-up appointment recently noted that the idea of having a health professional refer to her illness as a 'personality issue' was offensive. She noted that when first di- agnosed, she self-stigmatized and her ability to cope worsened. The patient in question seemed to struggle in particular with the idea that her illness was part of her 'personality', making her feel as though she could not overcome her struggles. This patient had been followed over a long period of time as both an inpatient and outpatient and longitudinally fulfilled criteria for the diagnosis of BPD. Although her comments raised some questions, I feel most uncomfortable regarding those who are diagnosed on the first meeting. The diagnosis of a personality disorder requires identification of a long-term pattern of specific behaviours, which is difficult to illicit in a single session. Additionally, some of the criteria on the McLean screening form are non-specific and context dependent: feelings of emptiness, lack of identity, and relationships troubled by arguments. I struggle with the idea that it is pathologic for a young adult in their late teens to struggle with identity or with relationships.

Putting my reservations aside, I recognize that diagnosis allows patients to access community DBT. I also understand the overwhelming load of patients that community psychiatrists take on and that longitudinal follow up may not be feasible in the current medical climate. Ultimately, I have taken away important lessons for myself when I am a primary care physician, whether in the ER or a community clinic:

1. Be aware of the stigma towards BPD patients and approach each patient with an open mind and a professional attitude.

2. Carefully examine the context of BPD symptoms before attributing their difficulties to a single diagnosis.

\section{REFERENCES}

1. American Psychiatric Association. Diagnostic and Statistical Manual of Mental Disorders (DSM V). 5th ed. Washington, DC: American Psychiatric Publishing; 2013. $663 \mathrm{p}$.

2. Grant BF, Chou SP, Goldstein RB, et al. Prevalence, correlates, disability, and comorbidity of DSM-IV borderline personality disorder: results from the Wave 2 National Epidemiologic Survey on Alcohol and Related Conditions. J Clin Psychiatry. 2008;69(4):533-45.

3. Zimmerman M, Rothschild L, Chelminski I. The prevalence of DSMIV personality disorders in psychiatric outpatients. Am J Psychiatry. 2005;162(10):1911-8.

4. Paris J. Implications of long-term outcome research for the management of patients with borderline personality disorder. Harv Rev Psychiatry. 2002;10(6):315-23.

5. van Den Bosch LMC, Koeter MWJ, Stijnen T, Verheul R, van Den Brink W. Sustained efficacy of dialectical behaviour therapy for borderline personality disorder. Behav Res Ther. 2005;43(9):1231-41.

6. O'Connell B, Dowling M. Dialectical behaviour therapy (DBT) in the treatment of borderline personality disorder. J Psychiatr Ment Health Nurs. 2014;21:518-25.

7. Sansone RA, Sansone LA. Responses of mental health clinicians to patients with borderline personality disorder. Innov Clin Neurosci. 2013;10(5-6):3943.

8. Markham D, Trower P. The effects of the psychiatric label 'borderline personality disorder' on nursing staff's perceptions and causal attributions for challenge behaviours. Br J Psychiatry. 2003;42:243-56.

9. Treloar AJC. A qualitative investigation of the clinical experience of working 


\section{Commentary}

with borderline personality disorder. NZ J Psychol. 2009;38(2):30-4.

10. Aviram RB, Brodsky BS, Stanley B. Borderline personality disorder, stigma, and treatment implications. Harv Rev Psychiatry. 2006;14(5):249-56.

11. Knaak S, Szeto ACh, Fitch K, Modgill G, Patten S. Stigma towards borderline personality disorder: effectiveness and generalizability of an anti-stigma program for healthcare providers using a pre-post randomized design. Borderline Personal Disord Emot Dysregul. 2015;2:9. 